\title{
NEURAL NETWORK MODELING OF GRINDING PARAMETERS OF DUCTILE CAST IRON USING MINIMUM QUANTITY LUBRICATION
}

\author{
N.S.M. Sahid ${ }^{1}$, M.M. Rahman ${ }^{1,2^{*}}$ and K. Kadirgama ${ }^{1}$ \\ ${ }^{1}$ Faculty of Mechanical Engineering, Universiti Malaysia Pahang \\ 26600 Pekan, Kuantan, Pahang, Malaysia \\ *Email: mustafizur@ump.edu.my \\ Phone: +6094246239; Fax: +6094246222 \\ ${ }^{2}$ Automotive Engineering Centre \\ Universiti Malaysia Pahang, 26600 Pekan, Pahang, Malaysia
}

\begin{abstract}
This paper presents the optimization of the grinding parameters of ductile cast iron in wet conditions and with the minimum quantity lubrication (MQL) technique. The objective of this project is to investigate the performance of ductile cast iron during the grinding process using the MQL technique and to develop artificial neural network modeling. In this project we used the DOE method to perform the experiments. Analysis of variance with the artificial neural network method is used to investigate significant effects on the performance characteristics and the optimal cutting parameters of the grinding process. Ductile cast iron was used in this experiment and the ethanol glycol was applied in the conventional method and compared with the MQL method. During conventional grinding, a dense and hard slurry layer was formed on the wheel surface and the performance of the ductile cast iron was very low, threatening the ecology and health of the workers. In order to combat the negative effects of conventional cutting fluids, the MQL method was used in the process to formulate modern cutting fluids endowed with user- and eco-friendly properties. Aluminum oxide was used as the grinding wheel (PSA-60JBV). This model has been validated by the experimental results of ductile cast iron grinding. Each method uses two passes single-pass and multiple-pass. The prediction model shows that depth of cut and table speed have the greatest effect on the surface roughness and material removal rate for the MQL technique with multiple-passes by showing improved surface roughness, preventing workpiece burning and enabling a more friendly environment. Thus, various other parameters need to be added for further experiments, such as the wheel speed, distance from the wheel to the workpiece zone contact, and the geometry of the nozzle.
\end{abstract}

Keywords: Grinding; cast iron; minimum quantity lubrication; artificial neural network; depth of cut.

\section{INTRODUCTION}

Grinding is a precision machining process which is widely used in the manufacture of components requiring fine tolerances and smooth finishes [1]. Therefore, the negative effect of high temperature on these parameters should be prevented [2]. The high heat generation in the grinding process is the major part of the energy is due to the workpiece. Abrasive interaction is addicted for elastic and plastic deformation of the workpiece surface, and just a small portion of this energy is really used for cutting the material and for chip formation. The coolant and lubricant medium, the topography of 
the grinding wheel, and grinding parameters have a major role in increasing this cutting portion of the total energy. Besides, the grinding parameters and grinding fluid specifications should be considered so that the possibility of the grain's interaction with the workpiece to perform the cutting process with lower plastic deformation is increased. In dry grinding, because of the lack of cutting fluid (in order to transfer the heat from the contact zone), problems frequently occur in terms of thermal damage on the workpiece surface, high grinding energy and forces, high wear rate of the grinding wheel, low material removal rate (regarding relatively low depths of cut), as well as poor surface integrity compared with conventional flood grinding. In MQL grinding, an air-oil mixture called an aerosol is fed into the grinding contact zone. Compared with dry grinding, MQL grinding considerably enhances cutting performance in terms of increasing the wheel life and improving the surface quality of the ground parts [3]. Application of the MQL technique can reduce the grinding forces, energy consumption, wheel wear, and production costs, as well as generating a finer surface finish and improved surface integrity compared with dry and conventional flood conditions. Shen and [4] studied the wheel wear and tribological characteristics in wet, dry, and MQL grinding of a cast iron. The authors used water-based alumina and diamond nanofluids in the MQL grinding process and compared the grinding results with those of pure water. They verified the benefits of nanofluids in terms of reducing grinding forces, improving surface roughness, and preventing burning of the workpiece. In contrast to dry grinding, MQL grinding could substantially lower the grinding temperature [1].

Ethylene glycol is used to supply a minute quantity of cooling lubricant medium to the contact point or to the zone so that the applied amount of grinding fluid can be reduced dramatically while maintaining the cooling and lubrication effects that are lost in dry machining. Furthermore, MQL is widely applied in cutting processes such as turning, milling, and drilling, although MQL grinding is still a relatively new research area. Traditionally, ethanol from corn has primarily been produced through dry- and wet-milling processes. The traditional dry-grind process grinds the whole corn kernel and mixes it with water and enzymes. The mash is then cooked to liquefy the starch further, and is then cooled and mixed with more enzymes to convert the remaining sugar polymers to glucose before fermenting to ethanol [5]. The components of the kernel that are not fermented include the germ, fiber, and protein, and these are concentrated in the distillers' dried grains that are produced as co-products. While dry milling is less capital intensive, it also yields less ethanol per bushel of corn than wet milling [6]. The grinding process generates an extremely high input of energy per unit volume of material removed. Almost all this energy is converted to heat, which can cause high temperatures and thermal damage to the workpiece, such as workpiece burn, phase transformations, undesirable residual tensile stresses, cracks, reduced fatigue strength, and thermal distortion and inaccuracies. Besides that, the complete elimination of grinding fluids always makes it difficult to keep the grinding wheel's pores clean and then the grinding wheel is easily clogged. Furthermore, the use of cutting fluid has some drawbacks mainly concerning health hazards, since the worker is sometimes exposed to direct skin contact or inhalation of cutting fluid vapors [7]. The angle and geometry of the nozzle, if incorrectly positioned, causes the flow of fluids in areas other than the surface of the workpiece. The alternative is to overcome this problem by using grinding fluids that are often applied for flood or minimum quantity lubrication. The objectives of this project are to investigate the performance of ductile cast iron during the grinding process using the MQL technique and to optimize the grinding parameters of ductile cast iron using the ANN method. 


\section{METHODS AND MATERIALS}

The overall work flow progress of the ductile cast iron using MQL during the grinding process, based on design of experiment, and the development of an artificial neural network to predict the surface roughness and material removal rate, are presented in this section. Experiments have been performed in order to investigate the effects of machining parameters (speed and depth of cut) on the surface roughness and material removal rate of the machined surface. Nine specimens of ductile cast iron, $30 \mathrm{~mm}$ length, $30 \mathrm{~mm}$ height and $5 \mathrm{~mm}$ width, were used for experimentation using grinding machines. All experiments were done under conventional coolant and MQL systems. Each experiment used the same machine with different flow rates of the system. The flow rates used are $36 \mathrm{ml} /$ hour, $72 \mathrm{ml} /$ hour and $144 \mathrm{ml} /$ hour. The concentration for conventional coolant used was $5 \%$ of ethanol with fully synthetic, while for MQL the concentration used was $0.15 \%$. Table 1 shows the design of experiment matrix for this study.

Table 1. Design of experiment.

\begin{tabular}{ccc}
\hline Sample & Table speed $(\mathrm{rpm})$ & Depth of cut $(\mu \mathrm{m})$ \\
\hline 1 & 25.2 & 2 \\
2 & 25.2 & 4 \\
3 & 25.2 & 6 \\
4 & 12.5 & 2 \\
5 & 12.5 & 4 \\
6 & 12.5 & 6 \\
7 & 8.7 & 2 \\
8 & 8.7 & 4 \\
9 & 8.7 & 6 \\
\hline
\end{tabular}

During the grinding process, a Supertec precision machine was used, model STP-102AADCII. A vitrified bond aluminum oxide was used as the grinding wheel (PSA-60JBV), with the grain size as the average abrasive size. The workpiece used was ductile cast iron with carbon content of 3.5\%-3.9\% and average hardness of 110Rockwell C. The dimensions of the specimens of cast iron were $30 \mathrm{~mm} \times 30 \mathrm{~mm} \times 5$ $\mathrm{mm}$. The two types of coolant used were conventional and minimum quantity lubrication. In conventional coolants, the concentration of ethanol was $2.5 \%$, at a flow rate of $2.83 \times 10^{-4} \mathrm{~m}^{3} / \mathrm{s}$. The device for application of MQL is composed of an air compressor, pressure regulator, flow rate meter and nozzle. In this experiment, the air pressure was $0.6 \mathrm{MPa}$, and the fluid flow rate was $36 \mathrm{ml} / \mathrm{hour}, 72 \mathrm{ml} /$ hour and 144 $\mathrm{ml} /$ hour. This device provides oil and allows control of oil/air flow rates individually. The air flow rate was monitored using a turbine-type meter, calibrated to a pressure of $8.0 \times 10^{5} \mathrm{~Pa}$. Figure 1 shows the experimental setup. 


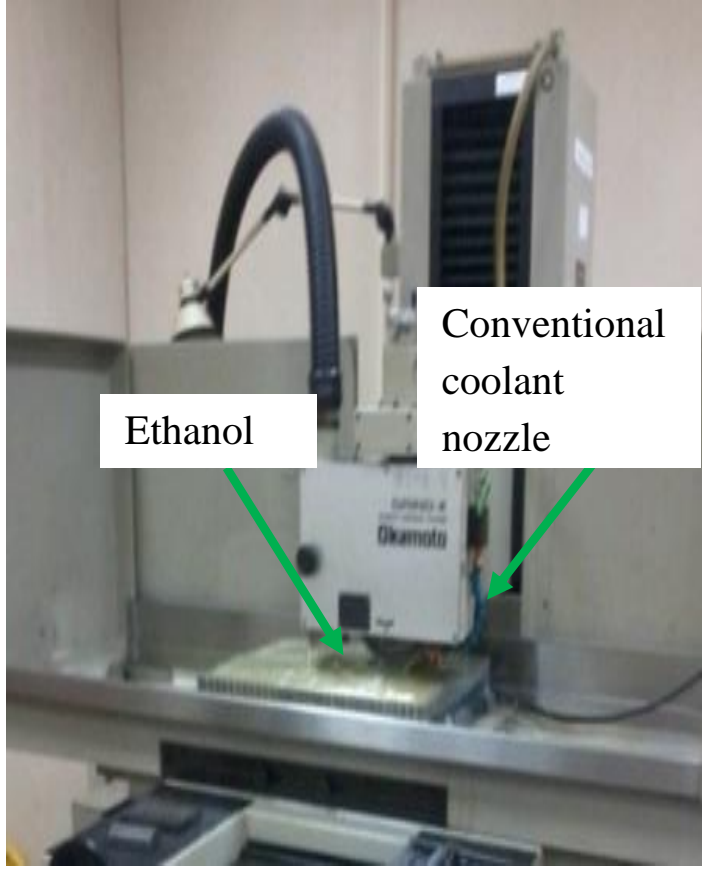

(a)

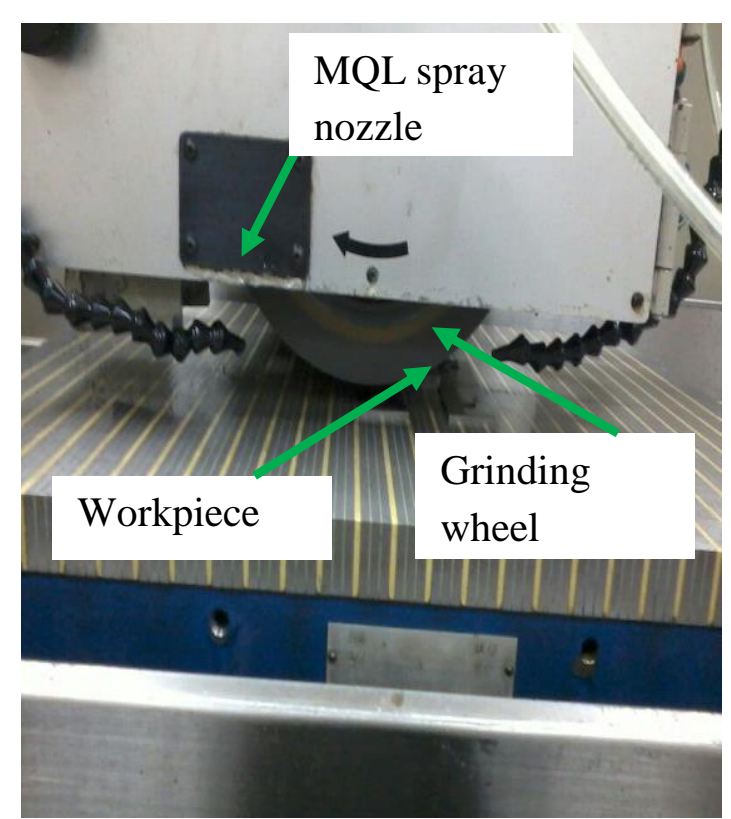

(c)

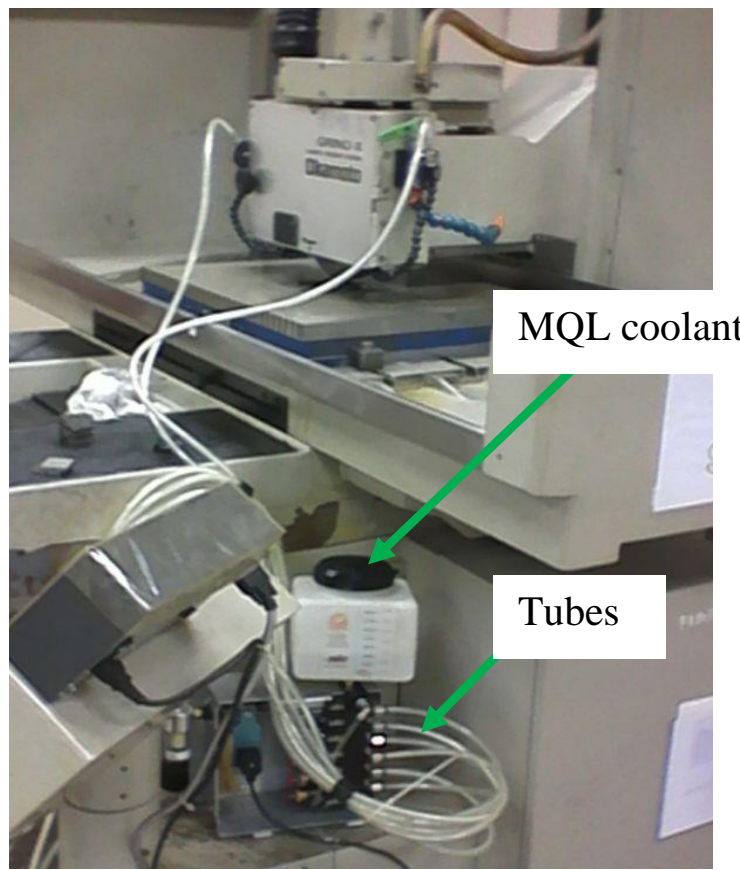

(b)

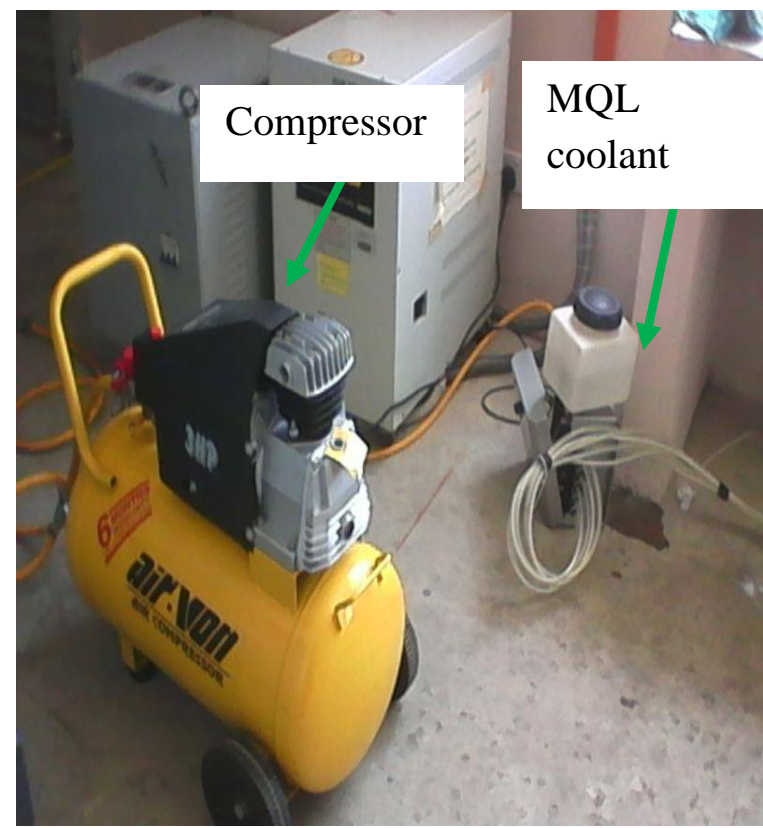

(d)

Figure 1. Experimental setup.

\section{ANN Modeling}

The experimental data consists of 27 samples with their respective grinding passes and types of coolant. The ANN model was trained using 16 randomly selected data (accounting for $60 \%$ of the total data), while the remaining 7 data (accounting for $25 \%$ each) were utilized for testing and $15 \%$ for validation of the network performance. There are many variations of the batch back-propagation algorithm. The simplest implementation of batch back-propagation learning updates the network weights and 
biases in the direction in which the function decreases most rapidly, the negative of the gradient. The weights and biases of the network are updated after the entire training set has been applied to the network. The gradients are calculated for each training example and added together to determine the change in the weights and biases. The main purpose of the batch back-propagation is to explain how to use the batch back-propagation training functions in the toolbox to train the feed-forward neural networks to solve specific problems [8]. Figure 2 shows the architecture for developing the ANN model. It has 2 inputs, 2 hidden layers and 2 output layers.

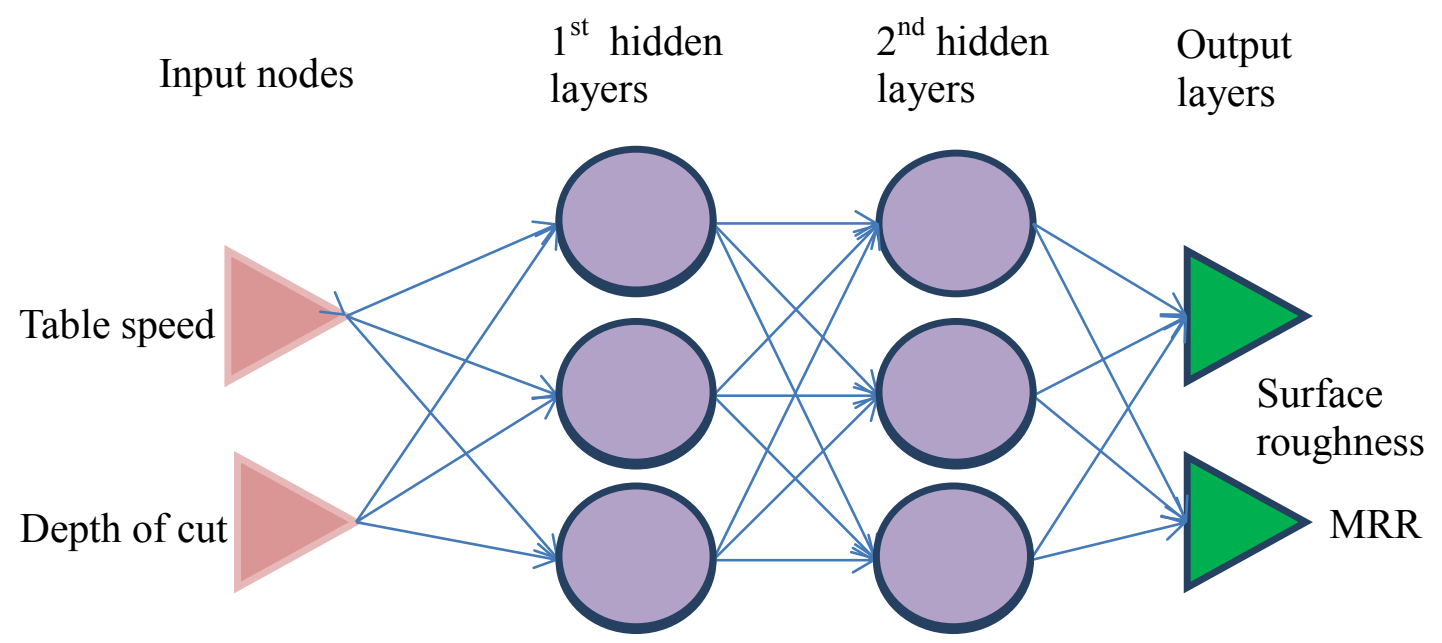

Figure 2. Architecture of the developed ANN model.

A multilayer perceptron with a different hidden layer feed-forward (FF) network is applied to correlate the input parameters to the surface roughness and material removal rate. The back-propagation learning algorithm uses recollected data to modify the connection weights appropriately. As a result, the error between the desired output, $T_{o}$ and actual output, $Y_{o}$ of the neural network is computed in the forward phase. An iterative error reduction is performed in a backward direction in the backward phase. Training and testing of the network are done using experimental data. The developed models are also verified experimentally. The fundamental relation between performance parameters and variable factors can be described as in Eq. (1) and Eq. (2):

$$
\begin{gathered}
Y=f(X, W) \\
v=\sum_{i} w_{i} x_{i}
\end{gathered}
$$

where $Y$ represents the performance parameter $(R a$ and $M R R) ; X$ is a vector of the input variables to the neural network; $W$ is the weight matrix that is evaluated in the network training process; $f($.) represents the model of the process that is to be built through NN training; $v$ is the induced local field produced at the input of the activation function; $x_{i}$ is the input signal and $w_{i}$ is the respective synaptic weight. The following relations were used to combine the inputs of the network at the nodes of the hidden layer and the output layer, respectively. 


$$
\begin{gathered}
H_{l}=f\left(v_{l}\right)=f\left(\sum_{i} w_{l i} x_{i}\right) \\
Z_{j}=f\left(H_{l}\right), O_{k}=f\left(Z_{j}\right) \text { and } Y_{o}=f\left(O_{k}\right)
\end{gathered}
$$

where $H_{l}, Z_{j}$ and $O_{k}$ are the output at the hidden layers one, two and three respectively; $Y_{o}$ is the output, $S R$ and $M R R$ at the output layer and $w_{l i}$ is the synaptic weight from input neuron $i\left(x_{i}\right)$ to the neuron $l$ in the first hidden layer. By combining Eqs. (1)-(4), the relation for the output of the network can be set as the following equation:

$$
Y_{o}=f\left(O_{k}\right)=f\left(\sum_{k} w_{o k} f\left(\sum_{j} w_{k j} f\left(\sum_{l} w_{j l} f\left(\sum_{i} w_{l i} x_{i}\right)\right)\right)\right)
$$

where $w_{j l}$ is the synaptic weight from neuron $l$ in the first hidden layer to the neuron $j$ in the second hidden layer, $w_{k j}$ is the synaptic weight from neuron $j$ in the second hidden layer to the neuron $k$ in the third hidden layer and $w_{o k}$ is the synaptic weight from neuron $k$ in the last hidden layer to the output neuron $o$. The outputs at the hidden layer $\left(H_{l}, Z_{j}\right.$ and $\left.O_{k}\right)$ and output layer $\left(Y_{o}\right)$ are calculated using the hyperbolic tangent function of the sigmoid function as in Eq. (6) because it yields practical benefits over the logistic function.

$$
f(v)=\tanh (v)
$$

Finally, the output of the network was compared with the measured performance of the process using a mean square error $(E)$ as in Eq. (7):

$$
E=\frac{1}{N} \sum_{o=1}^{N}\left(T_{o}-Y_{o}\right)^{2}
$$

The ANN was trained in a batch mode where its parameters were only updated after all the input-output pairs were presented. The Levenberg-Marquardt (L-M) algorithm was employed for the training, and the target performance goal (mean square difference between NN output and target output) was set at 0.001 . The maximum number of epochs (representation of the input or output pairs and the adjustment of $\mathrm{NN}$ parameters) was considered to be 10,000 .

\section{RESULTS AND DISCUSSION}

The experimental results of cylindrical grinding with the conventional and minimum quantity lubrication techniques are presented in this section. The ANN model is developed to predict the surface roughness and MRR. A multi-layer perceptron with back-propagation is used. Four types of experiments are performed on the grinding of ductile cast iron using conventional coolant and MQL coolants with single-pass and multiple-pass grinding. Table 2 presents the material removal rate of single-pass and multiple-pass cylindrical grinding for conventional coolants and the MQL technique. It can be observed that the material removal rate increases for both the single-pass and multiple-pass. The experiments were conducted nine times with various combinations of table speed and depth of cut. A 5\% volume concentration of ethanol and a $0.15 \%$ 
volume concentration of MQL were used in this study. It can be observed that the minimum MRR in single-pass grinding using the conventional coolant was $0.001 \mathrm{~g} / \mathrm{s}$ and $0.0301 \mathrm{~g} / \mathrm{s}$ for the MQL. On the other hand, the maximum value is $0.009 \mathrm{~g} / \mathrm{s}$ and $0.03 \mathrm{~g} / \mathrm{s}$ for the conventional coolant and MQL respectively. They were slightly different in multiple-pass grinding. The minimum MRR in multiple-pass grinding using a conventional coolant was $0.021 \mathrm{~g} / \mathrm{s}$; however, the minimum MRR was $0.023 \mathrm{~g} / \mathrm{s}$ for MQL. On the other hand, the maximum value is $0.042 \mathrm{~g} / \mathrm{s}$ and $0.071 \mathrm{~g} / \mathrm{s}$ for conventional coolant and MQL respectively. It can be observed that the MQL multiplepass gives a higher value compared to other methods. This shows that the MRR and surface roughness in the MQL multiple-pass method has the best performance.

Table 2. Experimental result for material removal rate.

\begin{tabular}{|c|c|c|c|c|c|c|}
\hline \multirow{3}{*}{$\begin{array}{l}\text { No. of } \\
\text { sample }\end{array}$} & \multirow{3}{*}{$\begin{array}{l}\text { Table } \\
\text { speed } \\
\text { (rpm) }\end{array}$} & \multirow{3}{*}{$\begin{array}{l}\text { Depth of } \\
\text { cut }(\mu \mathrm{m})\end{array}$} & \multicolumn{4}{|c|}{ Material removal rate $(\mathrm{g} / \mathrm{s})$} \\
\hline & & & \multicolumn{2}{|c|}{ Single-pass } & \multicolumn{2}{|c|}{ Multiple-pass } \\
\hline & & & $\begin{array}{c}\text { Conventional } \\
\text { coolant }\end{array}$ & MQL & $\begin{array}{l}\text { Conventional } \\
\text { coolant }\end{array}$ & MQL \\
\hline 1 & 25.2 & 2 & 0.008 & 0.00383 & 0.022 & 0.023 \\
\hline 2 & 25.2 & 4 & 0.003 & 0.00405 & 0.028 & 0.033 \\
\hline 3 & 25.2 & 6 & 0.002 & 0.00884 & 0.036 & 0.054 \\
\hline 4 & 12.5 & 2 & 0.004 & 0.00301 & 0.019 & 0.071 \\
\hline 5 & 12.5 & 4 & 0.002 & 0.00527 & 0.032 & 0.019 \\
\hline 6 & 12.5 & 6 & 0.001 & 0.00556 & 0.042 & 0.017 \\
\hline 7 & 8.7 & 2 & 0.001 & 0.00207 & 0.017 & 0.022 \\
\hline 8 & 8.7 & 4 & 0.003 & 0.0057 & 0.035 & 0.05 \\
\hline 9 & 8.7 & 6 & 0.002 & 0.00604 & 0.018 & 0.036 \\
\hline 10 & 25.2 & 2 & 0.016 & 0.00503 & 0.034 & 0.029 \\
\hline 11 & 25.2 & 4 & 0.014 & 0.00833 & 0.025 & 0.036 \\
\hline 12 & 25.2 & 6 & 0.001 & 0.023 & 0.009 & 0.039 \\
\hline 13 & 12.5 & 2 & 0.004 & 0.00367 & 0.018 & 0.09 \\
\hline 14 & 12.5 & 4 & 0.009 & 0.0096 & 0.014 & 0.019 \\
\hline 15 & 12.5 & 6 & 0.021 & 0.00937 & 0.038 & 0.016 \\
\hline 16 & 8.7 & 2 & 0.012 & 0.00324 & 0.021 & 0.027 \\
\hline 17 & 8.7 & 4 & 0.013 & 0.00844 & 0.012 & 0.029 \\
\hline 18 & 8.7 & 6 & 0.002 & 0.01265 & 0.025 & 0.036 \\
\hline 19 & 25.2 & 2 & 0.014 & 0.00486 & 0.026 & 0.022 \\
\hline 20 & 25.2 & 4 & 0.0082 & 0.00825 & 0.027 & 0.0354 \\
\hline 21 & 25.2 & 6 & 0.0016 & 0.01289 & 0.022 & 0.0452 \\
\hline 22 & 12.5 & 2 & 0.0039 & 0.00401 & 0.018 & 0.078 \\
\hline 23 & 12.5 & 4 & 0.0053 & 0.01072 & 0.021 & 0.024 \\
\hline 24 & 12.5 & 6 & 0.011 & 0.01041 & 0.019 & 0.026 \\
\hline 25 & 8.7 & 2 & 0.001 & 0.00322 & 0.024 & 0.03 \\
\hline 26 & 8.7 & 4 & 0.003 & 0.00913 & 0.025 & 0.099 \\
\hline 27 & 8.7 & 6 & 0.002 & 0.01266 & 0.027 & 0.105 \\
\hline
\end{tabular}


Figure 3 shows the MRR value effects of various combinations of the factors: table speed, depth of cut, type of grinding, and type of coolant. Multiple-pass grinding has a higher MRR compared to the single-pass because the grinding wheel only passes over the specimen once. On the other hand, for multiple-pass grinding, the grinding wheel passes ten times. However, when using MQL, the MRR was slightly lower than that of the conventional coolant. This is due to the particles having exceptional tribological properties, which can reduce friction under extreme pressure conditions [10].

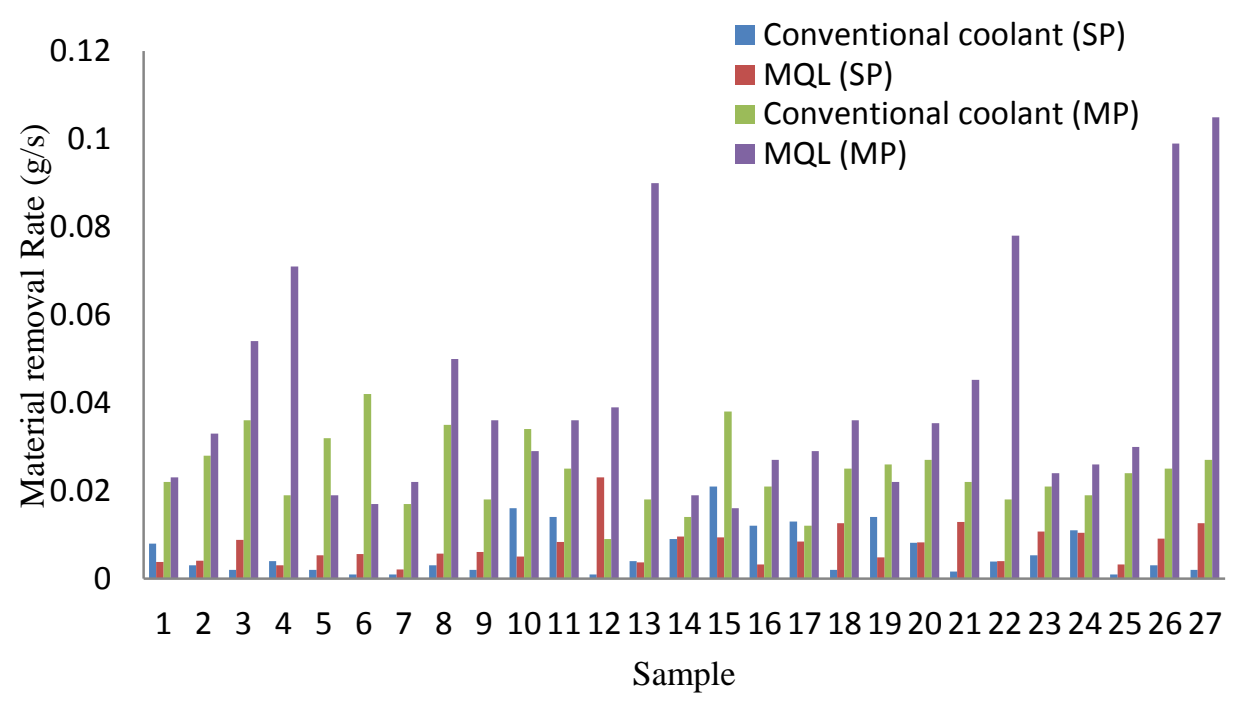

Figure 3. Material removal rate for each coolant and type of grinding.

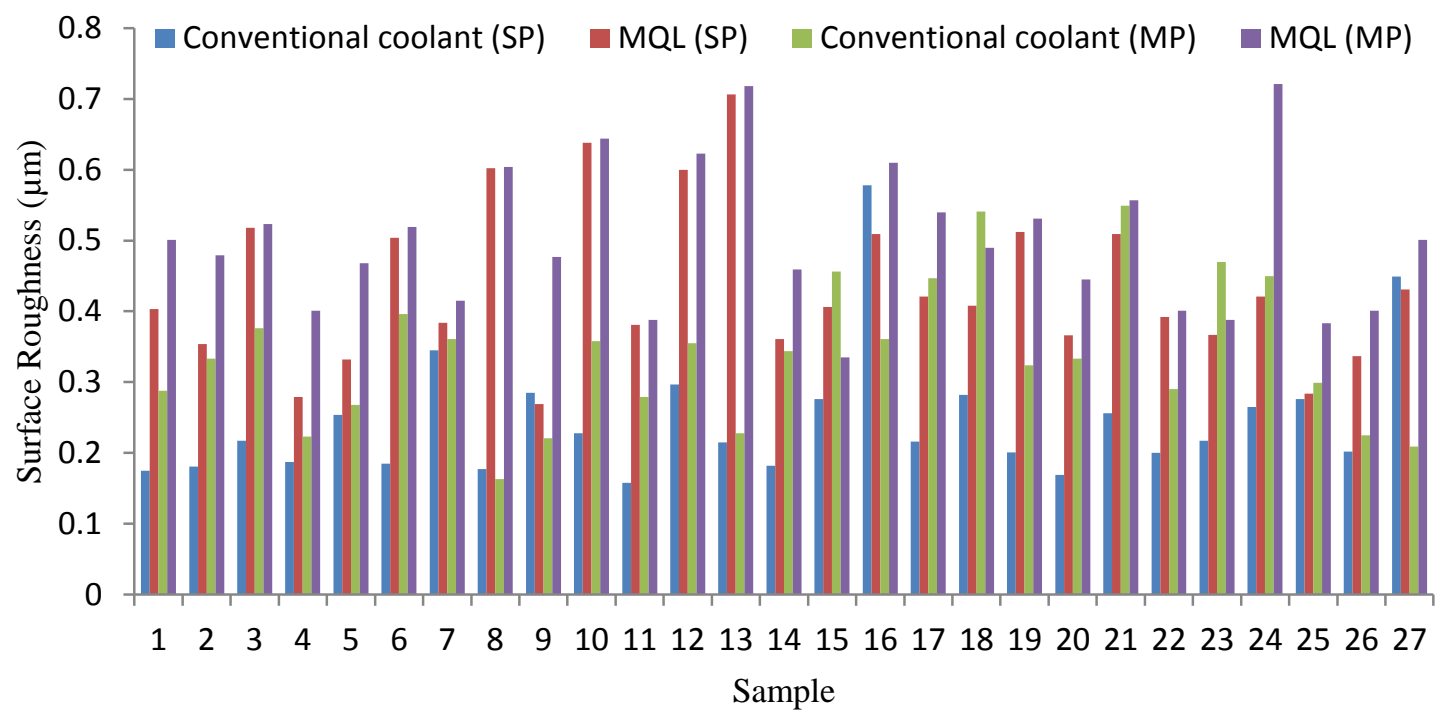

Figure 4. Surface roughness for each coolant and type of grinding.

Figure 4 shows the surface roughness value effects of various combinations of the factors: table speed, depth of cut, type of grinding, and type of coolant. Multiplepass grinding has a higher surface roughness compared to the single-pass because the grinding wheel only passes over the specimen once. From the results it was observed that the increased number of cutting passes makes the surface roughness increase 
consequently. There was a quite linear relationship between the number of cutting passes and surface roughness. As the number of cutting passes increases, this results in more material being removed and consequently a high grinding force. The grinding forces are an important quantitative indicator to characterize the mode of material removal because the specific grinding energy and the surface damage are strongly dependent on the grinding forces. Higher grinding forces result in increased friction. The friction of the grinding wheel increased the values of surface roughness [11].

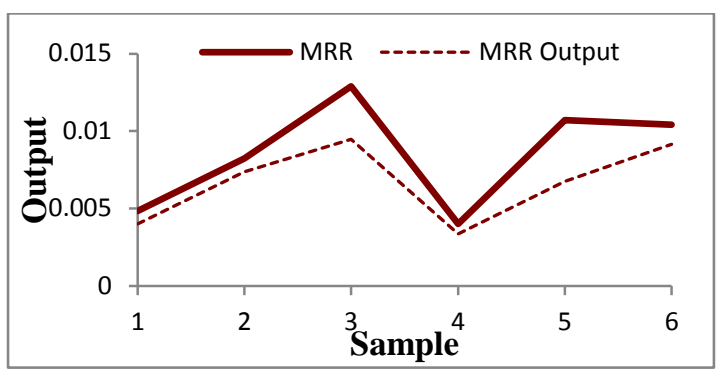

(a) MQL multiple-pass for MRR

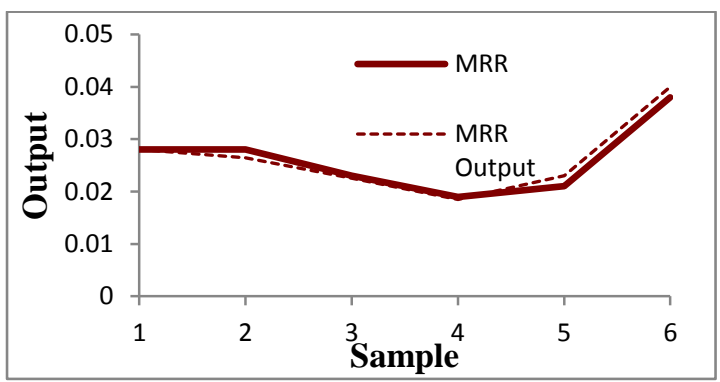

(c) MQL single-pass for MRR

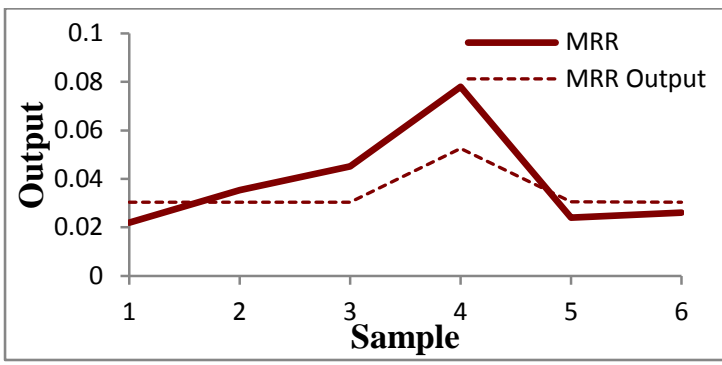

(e) Conventional single-pass for MRR

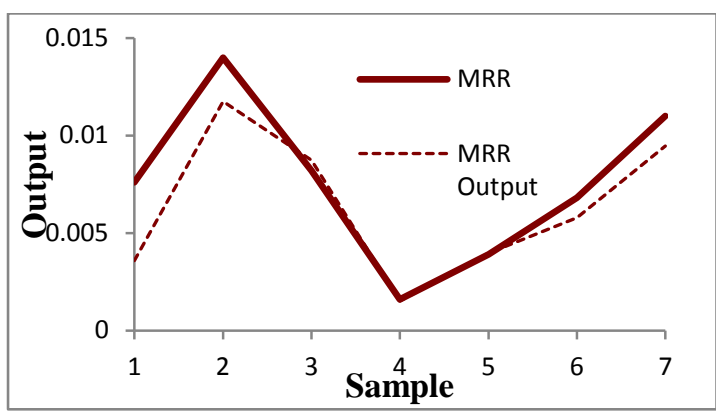

(g) MQL single-pass for MRR

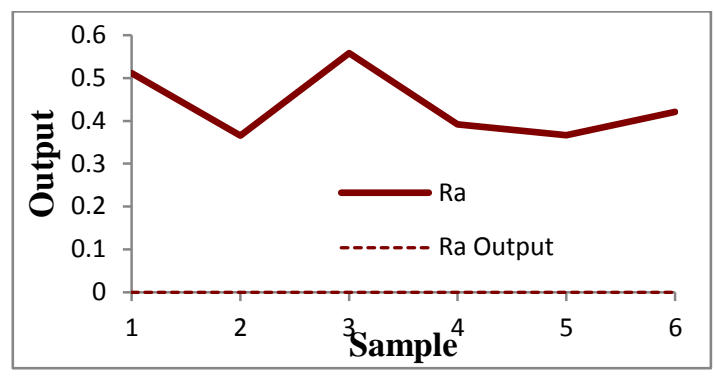

(b) MQL multiple-pass for Ra

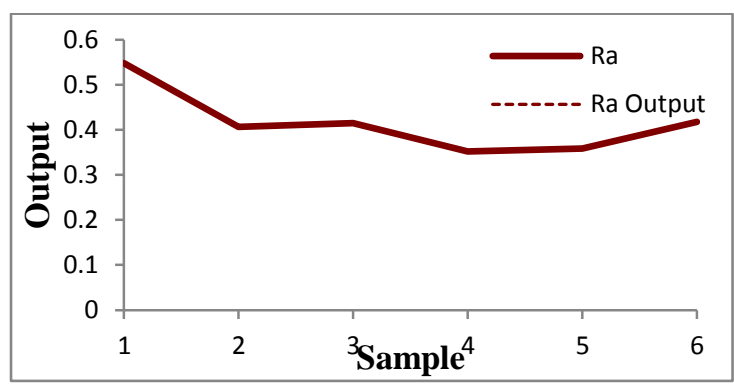

(d) MQL single-pass for Ra

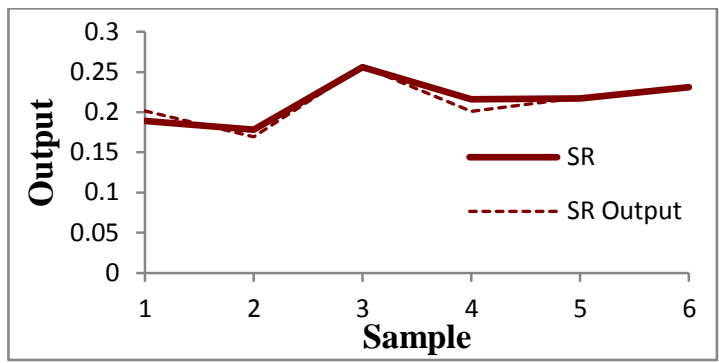

(f) Conventional single-pass for $\mathrm{Ra}$

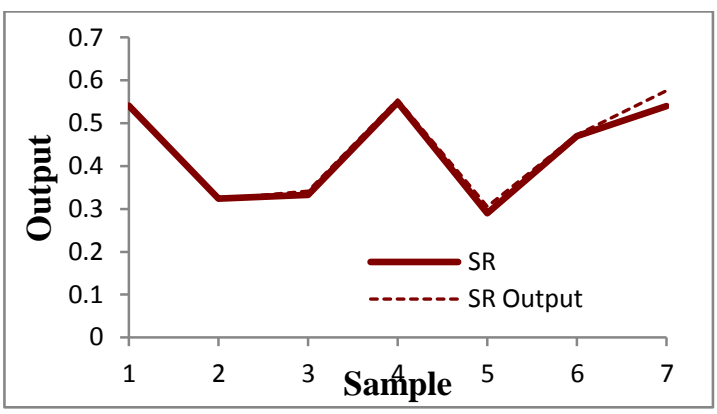

h) MQL single-pass for $\mathrm{Ra}$

Figure 5. Predicted values for each coolant and type of grinding. 
The ANN model was developed for predicting the surface roughness and material removal rate based on the multi-layer perceptron technique. The LevenbergMarquardt $(\mathrm{L}-\mathrm{M})$ algorithm was used for the training, and the target performance which is MSE was set to 0.001 [12]. The maximum number of epochs for demonstration of the input/output pairs and the modification of ANN parameters was considered to be 10,000. Figure 5 shows the actual versus predicted values for both systems, namely conventional and MQL for multiple-pass and single-pass by ANN analysis. The ANN model was trained on $60 \%$ of the total data, while $25 \%$ of the total data was used for testing and the remaining $15 \%$ was used for validation. It can be observed that most of the predicted data approximate with the actual data. The red line indicates the experimental value and the dashed line indicates the actual value (target output).

Table 3. Error analysis for the network of surface roughness.

\begin{tabular}{lcccc}
\hline & \multicolumn{3}{c}{ Conventional coolant } & \multicolumn{2}{c}{ MQL } \\
\cline { 2 - 5 } Performance & \multicolumn{3}{c}{ Surface roughness $(\mu \mathrm{m})$} \\
\hline & Single-pass & Multiple-pass & Single-pass & Multiple-pass \\
MSE & $2.90176 \times 10^{-5}$ & 0.00176 & $1.40126 \times 10^{-5}$ & 0.00126 \\
NMSE & 0.008272871 & 0.32435 & 0.004375871 & 0.22335 \\
MAE & 0.003719542 & 0.02398 & 0.002712542 & 0.02138 \\
Min Abs Error & 0.000367596 & 0.00192 & 0.000164596 & 0.00132 \\
Max Abs Error & 0.010301721 & 0.10034 & 0.010101421 & 0.10002 \\
$\mathrm{r}$ & 0.998236328 & 0.89156 & 0.99823768 & 0.901236 \\
\hline
\end{tabular}

Table 4. Error analysis for the network of material removal rate.

\begin{tabular}{lcccc}
\hline \multirow{2}{*}{ Performance } & \multicolumn{4}{c}{ Conventional coolant } \\
\cline { 2 - 5 } MSE & Single-pass & Multiple-pass & Single-pass & Multiple-pass \\
NMSE & 0.4716321 & 0.123632 & 0.4316321 & 0.134332 \\
MAE & 0.46149965 & 0.00688 & 0.4216465 & 0.00548 \\
Min Abs Error & 0.00187113 & 0.00322 & 0.00177113 & 0.00102 \\
Max Abs Error & 0.00040572336 & 0.00261 & 0.0021236 & 0.00222 \\
$\mathrm{r}$ & 0.99091562 & 0.99866 & 0.9923212 & 0.99826 \\
\hline
\end{tabular}

Tables 3 and 4 present the error analysis for the network of surface roughness and MRR within percentage relative errors in the verification cases. The tables show the actual versus predicted values for the conventional and MQL methods with single-pass and multiple-passes by ANN analysis. The ANN prediction yields the statistical coefficients, giving the linear correlation coefficient (r) value of 0.99 for both cases. The regression coefficients obtained from testing of the ANN were perfect and within the acceptable limits in both cases. As the correlation coefficient approaches 1, the accuracy of the prediction advances. Thus, the correlation coefficient range is very close to 1 , which consequently indicates excellent agreement between the experimental and the ANN predicted results [13]. 
The data is further analyzed for sensitivity to identify the influence of the varied input process parameters on the output material removal rate and response surface roughness. Tables 5 and 6 present the sensitivity analysis for the surface roughness and material removal rate respectively. From the result it is apparent that with the MQL multiple-pass system the surface roughness and material removal rate have more influence on both the performance of speed and depth of cut. The lowest influence of surface roughness and material removal rate on both the performance of speed and depth of cut was with a conventional single pass. It can be observed that MQL with multiple-passes shows more interaction between the input and output because increasing the cutting passes causes the material removal rate and surface roughness to have a greater effect.

Table 5. Sensitivity analysis value for surface roughness.

\begin{tabular}{ccccccccc}
\hline & \multicolumn{4}{c}{ Conventional coolant } & \multicolumn{4}{c}{ MQL } \\
\hline \multirow{3}{*}{ Sample } & \multicolumn{2}{c}{ Speed } & \multicolumn{2}{c}{ DOC } & \multicolumn{2}{c}{ Speed } & \multicolumn{2}{c}{ DOC } \\
\cline { 2 - 9 } & $\begin{array}{c}\text { Single } \\
\text { pass }\end{array}$ & $\begin{array}{c}\text { Multiple- } \\
\text { pass }\end{array}$ & $\begin{array}{c}\text { Single- } \\
\text { pass }\end{array}$ & $\begin{array}{c}\text { Multiple- } \\
\text { pass }\end{array}$ & $\begin{array}{c}\text { Single- } \\
\text { pass }\end{array}$ & $\begin{array}{c}\text { Multiple- } \\
\text { pass }\end{array}$ & $\begin{array}{c}\text { Single- } \\
\text { pass }\end{array}$ & $\begin{array}{c}\text { Multiple- } \\
\text { pass }\end{array}$ \\
\hline 1 & 0.2973 & 0.3143 & 0.3132 & 0.3134 & 0.3323 & 0.3058 & 0.0324 & 0.3136 \\
2 & 0.2974 & 0.3143 & 0.3129 & 0.3129 & 0.3321 & 0.3165 & 0.0323 & 0.3135 \\
3 & 0.2977 & 0.3144 & 0.3132 & 0.3129 & 0.3321 & 0.3272 & 0.0323 & 0.3137 \\
4 & 0.2980 & 0.3145 & 0.3134 & 0.3135 & 0.3286 & 0.3379 & 0.0237 & 0.3137 \\
5 & 0.2985 & 0.3146 & 0.3129 & 0.3130 & 0.3253 & 0.3384 & 0.0323 & 0.3135 \\
6 & 0.2992 & 0.3147 & 0.3130 & 0.3129 & 0.3223 & 0.3387 & 0.0323 & 0.3132 \\
7 & 0.2999 & 0.3148 & 0.3132 & 0.3133 & 0.3195 & 0.3486 & 0.0323 & 0.3132 \\
8 & 0.2998 & 0.3150 & 0.3128 & 0.3129 & 0.3170 & 0.3483 & 0.0323 & 0.3132 \\
9 & 0.2900 & 0.3152 & 0.3127 & 0.3129 & 0.3148 & 0.3475 & 0.0323 & 0.313 \\
\hline
\end{tabular}

Table 6. Sensitivity analysis value for material removal rate

\begin{tabular}{ccccccccc}
\hline & \multicolumn{4}{c}{ Conventional coolant } & \multicolumn{4}{c}{ MQL } \\
\hline \multirow{3}{*}{ Sample } & \multicolumn{2}{c}{ Speed } & \multicolumn{2}{c}{ DOC } & \multicolumn{2}{c}{ Speed } & \multicolumn{2}{c}{ DOC } \\
\cline { 2 - 9 } & $\begin{array}{c}\text { Single- } \\
\text { pass }\end{array}$ & $\begin{array}{c}\text { Multiple- } \\
\text { pass }\end{array}$ & $\begin{array}{c}\text { Single- } \\
\text { pass }\end{array}$ & $\begin{array}{c}\text { Multiple- } \\
\text { pass }\end{array}$ & $\begin{array}{c}\text { Single- } \\
\text { pass }\end{array}$ & $\begin{array}{c}\text { Multiple- } \\
\text { pass }\end{array}$ & $\begin{array}{c}\text { Single- } \\
\text { pass }\end{array}$ & $\begin{array}{c}\text { Multiple- } \\
\text { pass }\end{array}$ \\
\hline 1 & 0.0204 & 0.0209 & 0.0302 & 0.0312 & 0.0324 & 0.0332 & 0.0324 & 0.0312 \\
2 & 0.0203 & 0.0201 & 0.0312 & 0.0314 & 0.0322 & 0.0331 & 0.0323 & 0.0331 \\
3 & 0.0204 & 0.0207 & 0.0332 & 0.0319 & 0.0324 & 0.0330 & 0.0313 & 0.0321 \\
4 & 0.0204 & 0.0213 & 0.0304 & 0.0313 & 0.0239 & 0.0330 & 0.0237 & 0.0330 \\
5 & 0.0206 & 0.0217 & 0.0351 & 0.0316 & 0.0328 & 0.0329 & 0.0323 & 0.0329 \\
6 & 0.0206 & 0.0201 & 0.0304 & 0.0319 & 0.0322 & 0.0328 & 0.0353 & 0.0328 \\
7 & 0.0206 & 0.0202 & 0.0301 & 0.0318 & 0.0321 & 0.0327 & 0.0324 & 0.0327 \\
8 & 0.0207 & 0.0207 & 0.0304 & 0.0316 & 0.0323 & 0.0326 & 0.0329 & 0.0326 \\
9 & 0.0207 & 0.0202 & 0.0302 & 0.0314 & 0.0325 & 0.0325 & 0.0327 & 0.0325 \\
\hline
\end{tabular}

Tables 7 and 8 present the error of surface roughness and material removal rate predicted values in the ANN for the conventional and MQL systems respectively. It can be observed that the predicted values of surface roughness with the single-pass method 
have an average total error of $0.34 \%$ and $0.07 \%$ for the conventional coolant and MQL systems respectively. However, in multiple-pass the average total error is $0.49 \%$ and $0.05 \%$ for the conventional and MQL systems respectively. It can be observed that the multiple-pass for MQL gives the lowest error. The error for the material removal rate is observed to be $4.954 \%$ and $1.743 \%$ in single-pass for the conventional and MQL systems respectively. For the multiple-pass, the error values are $6.047 \%$ and $1.362 \%$ for the conventional and MQL systems respectively. It can be observed that the MQL multiple-pass for both the surface roughness and material removal rate yields the minimum total error for the predicted values.

Table 7. Error for predicted value of surface roughness in ANN.

\begin{tabular}{ccccccc}
\hline No & Experimental & NN predicted & $\begin{array}{c}\text { Error } \\
(\%)\end{array}$ & Experimental & NN predicted & $\begin{array}{c}\text { Error } \\
(\%)\end{array}$ \\
\hline \multicolumn{7}{c}{ Conventional coolant } \\
\hline \multicolumn{7}{c}{ Single-pass } \\
\hline 1 & 0.52 & 0.512 & 1.53 & 0.489 & 0.486 & 0.61 \\
2 & 0.367 & 0.366 & 0.27 & 0.548 & 0.545 & 0.54 \\
3 & 0.557 & 0.558 & 0.17 & 0.441 & 0.445 & 0.90 \\
4 & 0.392 & 0.22 & 0.395 & 0.398 & 0.75 \\
& 0.391 & Average total & 0.34 & Average total & 0.07 \\
\hline \multicolumn{7}{c}{ Multiple-pass } \\
\hline 1 & 0.285 & 0.282 & 1.05 & 0.543 & 0.541 & 0.36 \\
2 & 0.2015 & 0.201 & 0.24 & 0.323 & 0.324 & 0.30 \\
3 & 0.1695 & 0.169 & 0.29 & 0.331 & 0.333 & 0.60 \\
4 & 0.257 & 0.256 & 0.38 & 0.5545 & 0.549 & 0.99 \\
& Average total & 0.49 & Average total & 0.05 \\
\hline
\end{tabular}

Table 8. Error for predicted value of surface roughness in ANN.

\begin{tabular}{|c|c|c|c|c|c|c|}
\hline No. & Experimental & NN predicted & Error $(\%)$ & Experimental & NN predicted & Error $(\%)$ \\
\hline \multicolumn{4}{|c|}{ Conventional coolant } & \multicolumn{3}{|c|}{ MQL } \\
\hline \multicolumn{7}{|c|}{ Single-pass } \\
\hline 1 & 0.025 & 0.023 & 8.000 & 0.0456 & 0.044 & 3.508 \\
\hline 2 & 0.026 & 0.028 & 7.692 & 0.0256 & 0.0251 & 1.953 \\
\hline 3 & 0.027 & 0.0265 & 1.852 & 0.0354 & 0.0351 & 0.847 \\
\hline \multirow[t]{2}{*}{4} & 0.022 & 0.0225 & 2.27 & 0.0452 & 0.0455 & 0.664 \\
\hline & & Average total & 4.954 & & Average total & 1.743 \\
\hline \multicolumn{7}{|c|}{ Multiple-pass } \\
\hline 1 & 0.001 & 0.002 & 0 & 0.00486 & 0.00472 & 2.881 \\
\hline 2 & 0.014 & 0.012 & 14.28 & 0.00825 & 0.00819 & 0.727 \\
\hline 3 & 0.0082 & 0.0085 & 3.658 & 0.01289 & 0.01278 & 0.853 \\
\hline \multirow[t]{2}{*}{4} & 0.0016 & 0.0015 & 6.25 & 0.00406 & 0.00402 & 0.985 \\
\hline & & Average total & 6.047 & & Average total & 1.362 \\
\hline
\end{tabular}




\section{CONCLUSIONS}

In order to optimize the two parameters to produce the minimum surface roughness and maximize the MRR value in the experiment, the combination of table speed and depth of cut influences the process. The grinding process with MQL coolants gives the best performance compared to conventional coolants according to the output, which is the material removal rate and surface roughness. From the sensitivity analysis, it is concluded that MQL multiple-pass has the highest influence on depth of cut and table speed compared to the conventional single pass, conventional multiple-pass and MQL single pass. This is because the MQL multiple-pass method increases the number of cutting passes so that the surface roughness and material removal rate will have a greater influence on the table speed and depth of cut. Meanwhile, the conventional multiple-pass method has less influence even though the cutting speed is increased, because the coolants used in the conventional technique are less effective than the MQL system.

\section{ACKNOWLEDGMENTS}

The authors would like to acknowledgements Ministry of Education Malaysia and Universiti Malaysia Pahang for providing laboratory facilities and financial support under project no. RDU120310.

\section{REFERENCES}

[1] Shen BS, Albert J and Tung, Simon C. Application of nanofluids in minimum quantity lubrication grinding. Tribology Transactions. 2008;51:730-7.

[2] Hadad MH, Mostafa. An investigation on surface grinding of hardened stainless steel S34700 and aluminum alloy AA6061 using minimum quantity of lubrication (MQL) technique. The International Journal of Advanced Manufacturing Technology. 2013;68:2145-58.

[3] Astakhov VP. Ecological machining: near-dry machining. Machining: Springer; 2008. p. 195-223.

[4] Shen BS, Albert J. Minimum quantity lubrication (MQL) grinding using vitrified CBN wheels. The North American Manufacturing Research Institution of SME. 2009;37:129-36.

[5] Murthy GSS, Vijay Johnston, David B Rausch, Kent D Tumbleson, ME. Evaluation and strategies to improve fermentation characteristics of modified dry-grind corn processes. Cereal Chemistry. 2006;83:455-9.

[6] Rajagopalan SP, Elankovan McCalla, Darold Stowers, Mark. Enhancing profitability of dry mill ethanol plants. Applied Biochemistry and Biotechnology. 2005;120:37-50.

[7] Belentani RdMFJ, Hamilton Canarim, Rubens Chinali Diniz, Anselmo Eduardo Hassui, Amauri Aguiar, Paulo Roberto Bianchi, Eduardo Carlos. Utilization of minimum quantity lubrication (MQL) with water in CBN grinding of steel. Materials Research. 2014;17:88-96.

[8] Rahman MK, Md Ashikur Rahman Kadirgama, K Bakar, Rosli A. Prediction of material removal rate for Ti-5Al-2.5 Sn in EDM using multi-layered perceptron neural network technique. Proceedings of the 12th WSEAS international conference on Neural networks, fuzzy systems, evolutionary computing \& 
automation: World Scientific and Engineering Academy and Society; 2011. p. 17-23.

[9] Zhang H, Wu Q, Lin J, Chen J, 124304. ZXAP. Thermal conductivity of polyethylene glycol nanofluids containing carbon coated metal nanoparticles. Journal of Applied Physics. 2010;108:124304-9.

[10] Rahman MK, K. Performance of water-based zinc oxide nanoparticle coolant during abrasive grinding of ductile cast iron. Journal of Nanoparticles. $2014 ; 2014$.

[11] Xu XY, YQ Xu, HJ. Effect of grinding temperatures on the surface integrity of a nickel-based superalloy. Journal of Materials Processing Technology. 2002;129:359-63.

[12] Ashikur MK, Rahman Kadirgama, Kumaaran Rosli, A Bakar. Artificial intelligence model to predict surface roughness of Ti-15-3 alloy in EDM process. World Academiy of Science, Engineering and Technology. 2011;74.

[13] Rahman MK, K Ab Aziz, Azma Salwani. Artificial neural network modeling of grinding of ductile cast iron using water based $\mathrm{SiO} 2$ nanocoolant. International Journal of Automotive and Mechanical Engineering. 2014;9:1649-61. 